\title{
Римский Статут Международного уголовного суда: возможные вопросы конституционности ${ }^{*}$
}

Тузмухамедов Б.P.**

На страницах нашего журнала уже появлялись материалы, посвященные Статуту Международного уголовного суда' ${ }^{\prime}$, который был принят Дипломатической конференцией полномочных представителей под эгидой ООН в Риме 17 июля 1998 г. и вступает в силу 1 июля текущего года. Автор предлагаемой вниманию читателей статьи не ставит перед собой задачу подробного анализа учредительного документа будушей международной организации. Наиболее подготовлены для этого лица, принимавшие непосредственное участие в переговорах, и их соображения представили бы несомненный интерес для нашей аудитории.

Цель нижеследующих заметок - попытаться выявить некоторые возможные коллизии между текстами Римского Статута и Конституции Российской Федерации и предложить варианты их урегулирования.

На день завершения работы над статьей(19 июля 2002 г.) шестьдесят воссемь государств ратифицировали Римский Статут Международного уголовного суда ${ }^{2}$. В их числе два постоянных члена Совета

* Статья основана на докладе, сделанном автором на заседании Экспертно-консультативного совета по международному праву при Председателе Государственной Думы Федерального Собрания РФ 12 декабря 2001 г. В материале выражена личная точка зрения автора, которая не обязательно совпадает с официальной позицией России. ** Тузмухамедов Бахтияр Раисович - доцент Дипломатической академии МИД России. ${ }^{1}$ См., например: Уильям Шабас. Международный уголовный суд: исторический шаг в деле борьбы с безнаказанностью, МЖМП 1999, №4, с. 14-33; Рольф Эйнар Фифе. Международный уголовный суд, МЖМП 2001, №1, с.60-87.

${ }^{2}$ Сведения из электронной базы данных неправительственной организации Коалиция в поддержку Международного уголовного суда (The Coalition for the International Criminal Court) - <http://www.iccnow.org>. C недавнего времени база данных ОOH, содержащая тексты и сведения о состоянии международных договоров, зарегистрированных в Секретариате $\mathrm{OOH}$, закрыта для свободного доступа. Тем самым исследователей лишили возможности получать оперативную информацию о действующих конвенционных источниках. Эта неразумная мера справедливо критикуется в литературе: см.: Philip Alston. Charging for Access to International Law Treaty Information: Time for the UN to Rethink a Perverse Initiative. - European Journal of International Law, Vol.12 (2001) No. 2, p.351-358. 
Безопасности ООН (Соединенное Королевство и Франция), такие влиятельные государства, как Германия, Италия, Канада, Южная Африка, Аргентина, и другие. Есть среди ратифицировавших Статут государств и единственный участник СНГ - это Таджикистан. Напомним, что для вступления данного договора в силу требовалось шестьдесят ратификаций.

Неоднократно перед государствами, как завершившими процедуру ратификации, так и приступившими к ней или находящимися на разных стадиях подготовки к ратификации, вставали вопросы соответствия Статута национальным конституциям ${ }^{3}$. Наиболее очевидными из них являются неприкосновенность высших должностных лиц и передача собственных граждан будущему Суду. Эти темы уже обсуждались представителями отечественной доктрины с участием коллег из стран СНГ на семинарах, организованных московской Делегацией Международного Комитета Красного Креста ${ }^{4}$.

По вполне понятным политическим причинам вокруг этих вопросов развернулась оживленная дискуссия, хотя, по нашему мнению, имеющийся нормативный материал, содержит вполне определенные правовые ответы на них. Достаточно сказать, что институт ответственности высших должностных лиц является, используя язык части 4 статьи 15 Конституции РФ, «составной частью российской правовой системы» с момента вступления в силу для СССР в 1954 г. Конвенции о предупреждении преступления геноцида и наказании за него 1948 г. ${ }^{5}$ Статья IV Конвенции говорит о наказании всех виновных в совершении деяний, составляюших преступление геноцида, «независимо от того, являются ли они ответственными по конституции правителями, должностными или частными лицами». Статья VI Конвенции предусматривает возможность того, что лица, обвиняемые в совершении преступления геноцида, могут быть судимы международным уголовным судом.

Здесь же уместно напомнить, что краткая и категоричная формулировка ст. 91 Конституции («Президент Российской Федерации облада-

${ }^{3}$ См.: Report on Constitutional Issues Raised by the Ratification of the Rome Statute of the International Criminal Court. Venice Commission, CE Doc. CDL-INF (2001) 1.

${ }^{4} \mathrm{CM}$., например: Международный уголовный суд: ратификация и имплементация на национальном уровне. Материалы региональной конференции, Москва, 20-22 марта 2001 r.

${ }^{5}$ Сборник действующих договоров, соглашений и конвенций, заключенных СССР с иностранными государствами. Вып. XVI.- М., 1957. С. 66-71. 
ет неприкосновенностью») получила толкование в Постановлении Конституционного Суда от 11 июля 2000 г. Конституционный Суд отнес неприкосновенность к числу правовых средств, «которые обеспечивают свободное и ответственное осуществление Президентом Российской Федерации принадлежащих ему конституционных полномочий и непрерывность функционирования института главы государства ${ }^{6}$. Таким образом, неприкосновенность Президента функциональна, сохраняется до тех пор, пока президентские полномочия осуществляются их носителем ответственно, и не равняется абсолютному иммунитету. Другое дело, что в реальной жизни порядок отрешения главы государства от должности сложен и является политическим и во многом политизированным процессом.

Что касается передачи Международному уголовному суду собственных граждан и совместимости института передачи с конституционным запретом выдачи собственных граждан (ч. 1 ст. 61), то, во-первых, Конституция оперирует обоими терминами - «выдача» в ч. 1 ст. $61^{7}$ и ч. 2 ст. 63 , и «передача» в ч. 2 ст. $63^{8}$. Исходя из презумпции осознанного употребления двух разных терминов авторами конституционного текста, можно полагать, что они отдавали себе отчет в том, что «передача» отлична от «выдачи».

Во-вторых, ст. 102 Римского Статута содержит простое и понятное разъяснение обоих терминов, которое при необходимости поможет уяснению этого различия: под «передачей» понимается «доставка лица государством в Суд в соответствии с настояшим Статутом», а под «выдачей» - «доставка лица одним государством в другое государство в соответствии с положениями международного договора, конвенции или национального законодательства».

В некоторых государствах, в том числе в таких устоявшихся демократиях, как Германия и Франция, ратификации предшествовало внесение поправок в конституцию.

${ }^{6}$ Собрание законодательства Российской Федерации, 17 июля 2000 г., № 29, ст. 3118. ${ }^{7}$ «Гражданин Российской Федерации не может быть выслан за пределы Российской Федерации или выдан другому государству».

${ }^{8}$ «В Российской Федерации не допускается выдача другим государствам лиц, преследуемых за политические убеждения, а также за действия (или бездействие), не признаваемые в Российской Федерации преступлением. Выдача лиц, обвиняемых в совершении преступления, а также передача осужденных для отбывания наказания в других государствах осуществляются на основе федерального закона или международного договора Российской Федерации». 
29 ноября 2000 г. в Германии была принята поправка к части 2 статьи 16 Основного закона, которой делается специальное исключение из ранее безусловного запрета на выдачу собственного гражданина за пределы Германии. Первоначальный текст («Ни один немец не может быть выдан за пределы Германии») был дополнен фразой: «Законом может быть предусмотрено иное правило, допускающее выдачу государству-члену Европейского Союза или международному суду, при условии соблюдения принципов правового государства» ${ }^{9}$

Французская Конституция 8 июля 1999 г. была дополнена статьей 53-2, гласящей: «Республика признает юрисдикцию Международного уголовного суда, как она предусмотрена положениями договора, подписанного 18 июля 1998 года» ${ }^{10}$.

В Чехии Палата депутатов уже отклоняла правительственный проект поправки к Конституции. Проект новой ст. 112а предусматривает изъятия из неприкосновенности высших должностных лиц, из правила невыдачи собственных граждан и из президентской прерогативы осуществлять помилование в тех случаях, когда возникает конкурирующая юрисдикция Международного уголовного суда" .

В ряде случаев ратификация была завершена после завершения процедуры конституционного надзора. Так было во Франции, где президент и премьер-министр обратились в Конституционный совет с запросом о соответствии Статута Конституции Республики ${ }^{12}$.

А вот заключение, вынесенное Конституционным Судом Украины, о несоответствии части десятой преамбулы и ст. 1 Статута частям первой и третьей ст. 124 Конституции уже не позволит ратифицировать договор этой страной без принятия соответствующих поправок. Суд счел, что Конституция Украины не допускает дополнения национальной судебной системы международным судебным органом'3.

${ }^{9}$ CM.: Progress Report by Germany and Appendices. The Implications for Council of Europe Member States of the Ratification of the Rome Statute of the International Criminal Court. Strasbourg, 20 July 2001, CE Doc. Consult/ICC(2001) 14.

${ }^{10}$ Цит. по: International Decisions, AJIL Vol.94 (2000), p.394, footnote 8.

"См.: Progress Report by Czech Republic. The Implications for Council of Europe Member States of the Ratification of the Rome Statute of the International Criminal Court. Strasbourg, 16 July 2001, CE Doc. Consult/ICC(2001) 10. См. также: The Coalition for the International Criminal Court. Country-by Country Ratification Status Report - <http://www.iccnow.org/ $\mathrm{html} /$ country.html\#c>.

${ }^{12}$ См. подробнее: International Decisions, AJIL Vol.94 (2000), p.391-396.

${ }^{13}$ Заключение Конституционного Суда Украины №3-в от 11 июля 2001 г. Текст в переводе на английский язык имеется в распоряжении автора. См. также: Progress Report 
Можно ли обнаружить расхождения между Конституцией Российской Федерации и Статутом Международного уголовного суда, и если да, то каковы их хотя бы гипотетические последствия? Начнем с основ конституционного строя.

В соответствии с российской Конституцией народ является носителем суверенитета и единственным источником власти (ч. 1 ст. 3), которую он осушествляет через органы государственной власти (ч. 2 ст. 3 ), включающие органы законодательной, исполнительной и судебной власти (ст. 10). Президент как глава государства и исполнительной власти, а также законодательные органы получают свои властные полномочия непосредственно от народа на основе свободных выборов. Судьи назначаются Президентом и свои полномочия напрямую от народа не получают. Способом народного участия в отправлении судебной власти являются коллегии присяжных заседателей. Правосудие в Российской Федерации осуществляется только судами, учрежденными в соответствии с Конституцией и Федеральным конституционным законом «О судебной системе Российской Федерации».

Международный суд, дополняющий национальные органы уголовной юстиции (часть десятая преамбулы, ст. 1 Статута) и осуществляющий свои функции и полномочия на российской территории (ч. 2 ст. 4 Статута) ни Конституции, ни Федеральному конституционному закону не известен. Его судьи не назначаются Президентом и они не подчиняются Конституции и закону Российской Федерации. Если под дополнительностью Международного уголовного суда по отношению к национальной юстиции понимается как минимум сосушествование, а как максимум - замещение первым второй, то такому суду пока не находится места в российской судебной системе и в учреждающих ее нормативных актах.

Теперь рассмотрим возможные расхождения между Статутом и российской Конституцией в сфере прав и свобод человека и гражданина.

На наш взгляд, осуществление ряда прав, предусмотренных Конституцией, может быть затруднено в случае, если перед Международным уголовным судом окажутся российские граждане.

В соответствии с ч. 2 ст. 47 Конституции РФ обвиняемый имеет право на рассмотрение его дела судом с участием присяжных. Статуту Международного уголовного суда институт присяжных не известен.

by Ukraine. The Implications for Council of Europe Member States of the Ratification of the Rome Statute of the International Criminal Court. Strasbourg, 9 August 2001, CE Doc. Consult/ICC(2001) 26. 
В соответствии с ч. 3 ст. 50 Конституции каждый осужденный имеет право просить о помиловании, причем осушествление помилования (п. «в» ст.89) является единоличным властным полномочием Президента. Российский гражданин, осужденный Международным уголовным судом, лишается права на помилование, а президент оказывается в условиях, когда он не в состоянии реализовать одно из своих полномочий.

Конституции РФ не известно право на амнистию, но, возможно, отражением конституционной прерогативы Государственной Думы объявлять амнистию является право осужденного ожидать амнистию. Трудно представить, как это ожидаемое право и упомянутая прерогатива Государственной Думы могли бы быть реализованы применительно к российскому гражданину, осужденному Международным уголовным судом.

Каждому российскому гражданину, хотя бы и в положении обвиняемого, находящемуся за пределами России, Конституция гарантирует защиту и покровительство со стороны государства (ч. 2 ст. 61). Какие способы защиты и покровительства в отношении российского гражданина, находящегося на скамье подсудимых или осужденного Международным уголовным судом, будут в распоряжении Российской Федерации?

Как обеспечить конституционное право обжалования в суд решений и действий органов государственной власти (ч. 1 ст. 46), если уж Международный уголовный суд дополняет национальные органы юстиции? Будет ли национальный суд вправе рассматривать такую жалобу, и как обеспечить исполнение его решения, вынесенного в пользу жалобщика? Сможет ли российский гражданин, чье дело будет рассматриваться Международным уголовным судом, реализовать свое конституционное право обращаться в межгосударственные органы по заците прав и свобод по исчерпании всех имеющихся внутригосударственных средств правовой зациты (ч. 3 ст. 46)? И, наконец, как обеспечить предусмотренную Конституцией (ст. 52), а не только Частью 8 Римского Статута, защиту прав потерпевших от злоупотребления властью и компенсацию причиненного ущерба?

Обратимся теперь к гипотетическим расхождениям в сфере прерогатив органов государственной власти. Собственно, о них уже говорилось: речь идет о конституционных полномочиях: Президента - осуществлять помилование и Государственной Думы - объявлять амнистию. 
В уже упомянутом Постановлении Конституционного Суда РФ от 11 июля 2000 г. (в том деле речь шла о толковании положений Конституции о досрочном прекрашении полномочий Президента), Суд заявил, что «никто не может присваивать властные полномочия Президента Российской Федерации, осушествляемые им единолично». Если нельзя присваивать такие полномочия, то, по-видимому, нельзя и ограничивать возможность такие полномочия осуществлять. Если это предположение верно, то, по аналогии, равным образом нельзя ограничивать полномочие Государственной Думы объявлять амнистию.

Если отмеченные гипотетические расхождения между Римским Статутом и Конституцией действительно могут воспрепятствовать ратификации этого договора, следовало бы своевременно принять меры к достижению совместимости обоих текстов.

Некоторые расхождения, возможно, могли бы быть урегулированы без изменения Конституции. Например, дополнительность Международного уголовного суда стала бы приемлемой с внесением поправки в Федеральный конституционный закон «О судебной системе». В нынешнем виде этот закон не содержит положения, адаптирующего к его нуждам ч. 4 ст. 15 Конституции. Включение в него общей формулировки о преимущественном применении правил международного договора в случае их расхождения с положениями данного закона создало бы основания для гармонизации Международного уголовного суда и российской судебной системы.

Регламентация права на рассмотрение дела судом с участием присяжных заседателей в соответствии с Конституцией должна быть осуществлена федеральным законом. Таким законом является Уголовнопроцессуальный кодекс РФ, вводимый в действие с 1 июля 2002 г. $^{14}$ Часть 3 ст. 1 УПК РФ воспроизводит формулировку ч. 4 ст. 15 Конституции РФ. Возможно, однако, что законодателю следовало бы пойти дальше и специально оговорить допустимость отсутствия присяжных заседателей в международной судебной процедуре.

Средством достижения компромисса между двумя актами, не требуюшего внесения поправок и дополнений, могла бы быть процедура ${ }^{14}$ Собрание законодательства Российской Федерации, 24 декабря 2001 г., № 52 (1-я часть), ст. 4921. Для отдельных положений УПК РФ предусмотрены иные сроки и порядок введения в действие, в том числе относительно повсеместного введения судов с участием присяжных заседателей - см.: Федеральный закон «О введении в действие Уголовно-процессуального кодекса Российской Федерации» №177-Ф3 от 18 декабря 2001 г. 
толкования Конституции, осуществленная Конституционным Судом РФ. Впрочем, Конституционный Суд прежде уже находил основания для отказа в истолковании некоторых положений Конституции, имеющих внешнеполитическое или международно-правовое значение. В 1995 г. Суд отказал Совету Федерации в просьбе дать толкование п. «г» ч. 1 ст. 102, относяшей к ведению Совета решение вопроса о возможности использования Вооруженных Сил за пределами территории России, а в 1996 г. не стал рассматривать по существу запрос Думы Чукотского автономного округа о толковании ст. 69 о гарантиях прав коренных малочисленных народов в соответствии с общепризнанными нормами и принципами международного права и международными договорами Российской Федерации ${ }^{15}$.

Иным путем стала бы процедура проверки конституционности Римского Статута. Однако такая процедура возможна лишь в отношении не вступившего в силу международного договора Российской Федерации. В этом случае Конституционному Суду пришлось бы сначала решить вопрос о содержании термина «не вступивший в силу международный договор Российской Федерации», чем ему еще не приходилось заниматься. Означает ли этот термин договор, вообще не вступивший в силу, или же под ним следует понимать договор, не вступивший в силу для Российской Федерации? От ответа на этот вопрос зависят сроки, в течение которых можно было бы подать такое обрашение, и готовность Конституционного Суда рассматривать его по сушеству. Однако ответ этот никто, кроме самого Конституционного Суда, никогда не даст.

При том, что эйфория, вызванная в части нашего международноправового цеха появлением в Конституции ч. 4 ст. 15, похоже, находится в состоянии ремиссии, приходится допустить, что многое из сказанного в этих заметках кто-то из коллег попытается опровергнуть, ссылаясь именно на этот фрагмент конституционного текста. Однако представляется, что положение о приоритетном применении международного договора не должно распространяться на ситуации, когда

${ }_{15}$ Определение Конституционного Суда РФ №115-О от 4 декабря 1995 г. «Об отказе в принятии к рассмотрению запроса Совета Федерации Федерального Собрания Российской Федерации о толковании пункта «г» части 1 статьи 102 Конституции Российской Федерации» и Определение Конституционного Суда РФ №106-О от 26 декабря 1996 г. «Об отказе в принятии к рассмотрению запроса Думы Чукотского автономного округа о толковании статьи 69 Конституции Российской Федерации». Определения не были опубликованы. 
договор умаляет права и свободы человека и гражданина. Конституция прямо запрещает издание таких законов (ч. 2 ст. 55), а значит можно допустить, что международному договору, отменяющему права и свободы, закрыт путь в российскую правовую систему.

Можно предвидеть возражения, основанные на ст. 79 Конституции, которой допускается участие России в межгосударственных объединениях и передача им части полномочий в соответствии с международными договорами. Однако такое участие возможно лишь постольку, поскольку оно не влечет ограничения прав и свобод и не противоречит основам конституционного строя.

Если же избрать путь конституционных поправок, которыми либо в самой общей форме признавалась бы юрисдикция Международного уголовного суда (такая поправка могла бы дополнить ч. 4 ст. 15, назовем это «французской моделью»), либо делались исключения из отдельных прав и свобод («германская модель»), необходимо учитывать следующее. Гипотетические поправки - общую или специальные, пришлось бы делать к Главам 1 и 2 Конституции. Согласие на их пересмотр может дать только Конституционное Собрание, и следствием такого согласия станет разработка проекта новой Конституции (см. ст.. 135 Конституции РФ).

Некоторые коллеги - как российские, так и иностранные, с которыми автор делился высказанными выше соображениями, упрекали его в непонимании и неприятии прогрессивных процессов в развитии международных норм и институтов. Но дело не в критике нового и непривычного международного органа уголовной юстиции с весьма обширными полномочиями. В конце концов, Международный уголовный суд будет замещать собой национальные органы в случае полного паралича или отсутствия последних. Хотелось бы надеяться, что такая перспектива нам не угрожает.

Однако решение о присоединении ко всякому международному договору, тем более к такому, который, как было показано выше, обладает потенциалом для вторжения в основы конституционного строя, в сферу прав и свобод человека, непременно должно быть не только осмысленным и просвещенным, но и осторожным. Правовая система, все еще находящаяся в состоянии становления, должна окрепнуть, выработать известный иммунитет, для того, чтобы органично и без ущерба для себя воспринимать новые и прогрессивные веяния. 